\title{
Synthesis of chiral cyclohexanes and carbasugars by 6-exo-dig radical cyclisation reactions
}

\author{
Rajeev K. Shrivastava* ${ }^{*}, 2$, Elise Maudru ${ }^{1}$, Gurdial Singh ${ }^{*}, 1,3$, \\ Richard H. Wightman ${ }^{4}$ and Keith M. Morgan ${ }^{4}$
}

\section{Full Research Paper}

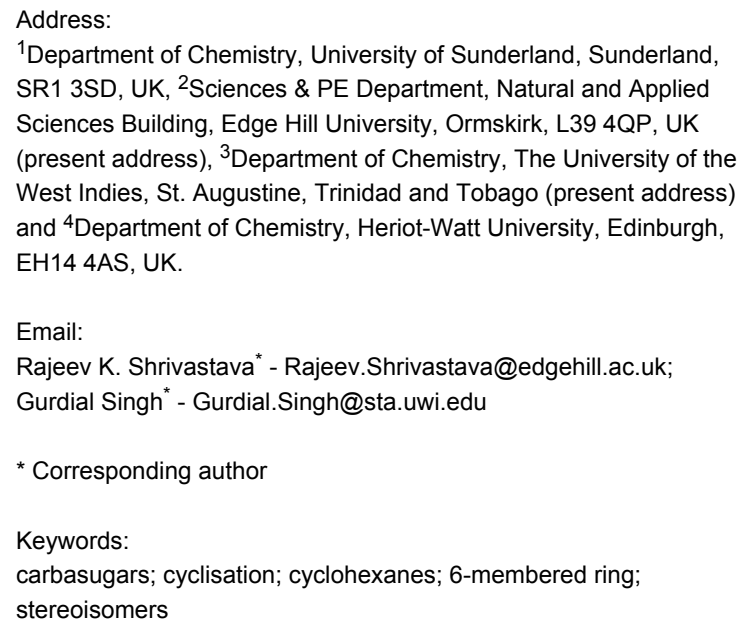

${ }^{1}$ Department of Chemistry, University of Sunderland, Sunderland, SR1 3SD, UK, ${ }^{2}$ Sciences \& PE Department, Natural and Applied Sciences Building, Edge Hill University, Ormskirk, L39 4QP, UK (present address), ${ }^{3}$ Department of Chemistry, The University of the West Indies, St. Augustine, Trinidad and Tobago (present address) and ${ }^{4}$ Department of Chemistry, Heriot-Watt University, Edinburgh, EH14 4AS, UK.

Email:

Rajeev K. Shrivastava* - Rajeev.Shrivastava@edgehill.ac.uk;

Gurdial Singh* - Gurdial.Singh@sta.uwi.edu

* Corresponding author

Keywords:

carbasugars; cyclisation; cyclohexanes; 6-membered ring;

stereoisomers

Beilstein Journal of Organic Chemistry 2008, 4, No. 43 doi:10.3762/bjoc. 4.43

Received: 09 September 2008

Accepted: 12 November 2008

Published: 19 November 2008

(c) 2008 Shrivastava et al; licensee Beilstein-Institut. License and terms: see end of document.

\begin{abstract}
Treatment of 5-(tert-butyldimethylsilyl)-2,3-O-isopropylidene-D-ribose with lithium acetylides gave mixtures of $s y n$ - and antialkynols 2a-2c which were separated following protection as methoxymethyl ethers. These were converted to the corresponding iodides which underwent 6-exo-dig radical cyclisation to afford chiral cyclohexanes and carbasugars. Oxidation of the primary alcohols 6a-b gave the corresponding aldehydes which on treatment with Grignard reagents afforded a mixture of alcohols. The corresponding iodides underwent similar 6-exo-dig cyclisation to give fully functionalised cyclohexanes.
\end{abstract}

\section{Introduction}

The use of carbohydrates as precursors for highly functionalised carbocyclic rings systems has found wide utility in organic synthesis [1-11]. In particular there is a large amount of literature devoted to the synthesis of cyclopentanes $[12,13]$ that employs a 5-exo-dig ring closure of a radical onto an alkyne [14]. In contrast there are fewer reports of the corresponding 6-exo-dig cyclisation to prepare fully functionalised cyclohexanes and carbasugars. The reason for this may be inferred from the observation that the formation of six-membered rings by a radical ring closure is some 40 times slower than the counterpart 5-hexenyl cyclisation [15-19]. In the case of the 6-hexenyl radical this results in the attack of the acyclic radical on the tin reagent becoming a more effective process compared to the 5-hexenyl case. An additional problem is that a 1,5-hydrogen abstraction leading to a resonance stabilised allylic radical is favourable, a reaction which may in fact be synthetically useful. 
We have previously reported the synthesis of cyclohexanes and carbasugars that uses a 6-exo-dig cyclisation [20] and herein we report on our current endeavours in this area.

\section{Results and Discussion}

Acetonisation [21] of D-ribose with acetone and hydrochloric acid afforded the corresponding acetonide $(72 \%)$ which was converted into silyl ether 1 ( $83 \%)$ by treatment with tertbutyldiphenylsilyl chloride (TBDPSCl) and triethylamine using DMAP as the catalyst. The silylated D-riboses 1 were treated with lithium phenylacetylide to give an inseparable mixture of diastereoisomeric diols 2a in 89\% yield (Scheme 1). Analysis of the ${ }^{1} \mathrm{H}$ NMR spectrum showed a 1:2 isomeric mixture of diastereoisomers, on the basis of integration of the tert-butyl group resonances, which were slightly separated (syn: $1.08 \mathrm{ppm}$ and anti: $1.09 \mathrm{ppm})$.

The stereochemistry at the new chiral centre was assigned on the basis of our previous findings [22]. The mixtures of diols 2 were treated with chloromethyl methyl ether to afford the corresponding MOM ethers, in a combined yield of $66 \%$. At this juncture we were able to separate the diastereoisomers, 3a (anti) and $\mathbf{3 b}$ (syn), by flash column chromatography on silica gel. Alternatively the syn isomer $\mathbf{3 b}$ could be prepared almost exclusively using D-ribonolactone as the starting material [23].

Desilylation of 3a was effective with TBAF in THF and afforded the primary alcohol $\mathbf{6 a}$ in $87 \%$ yield, which was converted to the corresponding iodide $7 \mathbf{a}$ with triphenylphosphine, imidazole and iodine [24]. Similar chemistry with the isomer $\mathbf{3 b}$ gave the alcohol $\mathbf{6 b}$ and subsequently the iodide $\mathbf{7 b}$ in comparable yields.

With the availability of the iodides $7 \mathbf{a}$ and $\mathbf{7 b}$ we investigated their radical cyclisation reactions. Treatment of $7 \mathbf{a}$ with tri- $n$ -

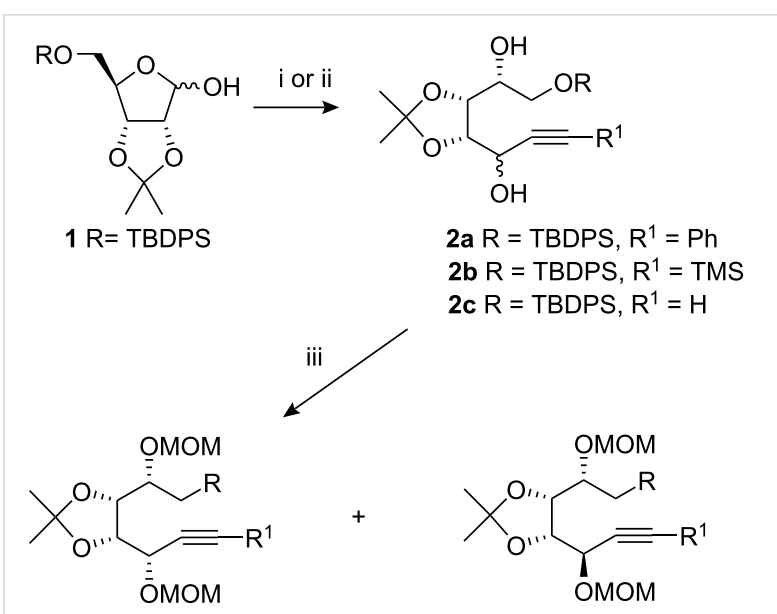

anti-(major) syn- (minor)

3a $\mathrm{R}=$ OTBDPS, $\mathrm{R}^{1}=\mathrm{Ph}(43 \%)$ 3b $\mathrm{R}=$ OTBDPS, $\mathrm{R}^{1}=\mathrm{Ph}(23 \%)$

4a $R=$ OTBDPS, $R^{1}=T M S$

5a $R=$ OTBDPS, $\mathrm{R}^{1}=\mathrm{H}$

4b $\mathrm{R}=$ OTBDPS, $\mathrm{R}^{1}=\mathrm{TMS}$ 5b $R=$ OTBDPS, $R^{1}=H$

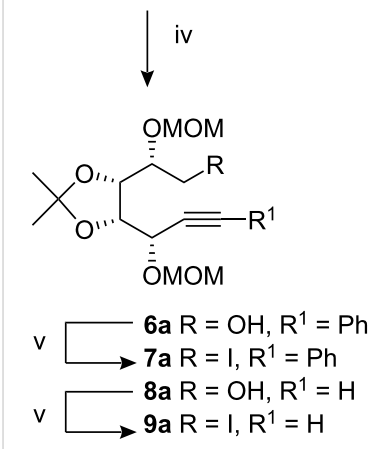

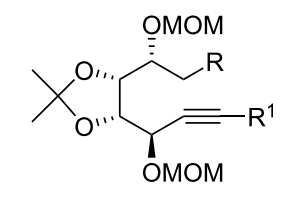

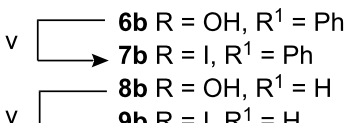

$\mathrm{v} \longrightarrow 9 \mathrm{~b} R=\mathrm{I}, \mathrm{R}^{1}=\mathrm{H}$

Scheme 1: Synthesis of iodides for radical cyclisation. Reagents and conditions: (i) LiC $\equiv \mathrm{CPh}, \mathrm{THF},-78^{\circ} \mathrm{C}$ to RT $12 \mathrm{~h}$; (ii) LiC $\equiv \mathrm{CTMS}$, THF, $-78{ }^{\circ} \mathrm{C}$; (iii) MOMCl, iPr ${ }_{2} \mathrm{NEt}, \mathrm{DCM}, 0^{\circ} \mathrm{C}$ to RT $48 \mathrm{~h}$; (iv) TBAF, THF, RT, 12 h; (v) I $2, \mathrm{PPh}_{3}, \mathrm{Im}$, PhMe, $\Delta$.

butyltin hydride and AIBN in refluxing benzene afforded (Scheme 2) the 6-exo-cyclisation [25-28] products $\mathbf{1 0}$ in $93 \%$ yield as an inseparable mixture of $E$ and $Z$ geometric isomers in<smiles>CO[C@@H](C#Cc1ccccc1)[C@@H]1OC(C)(C)O[C@@H]1[C@@H](CI)OC</smiles><smiles>COC(C#Cc1ccccc1)[C@@H]1OC(C)(C)O[C@@H]1[C@@H](CI)OC</smiles><smiles>CO[C@H]1/C(=C\c2ccccc2)C[C@H](OC)[C@H]2OC(C)(C)O[C@@H]12</smiles><smiles>CO[C@H]1C/C(=C/c2ccccc2)[C@@H](OC)[C@@H]2OC(C)([14CH3])O[C@H]12</smiles> 


\begin{tabular}{|c|c|c|c|}
\hline Proton & Chemical shift (ppm) & Multiplicity & Coupling constants $(\mathrm{Hz})$ \\
\hline $6 \beta-\mathrm{H}$ & 2.39 & dd & $J_{\text {gem }} 12.5$ and $J_{6 \beta, 5} 5.3$ \\
\hline $6 \alpha-\mathrm{H}$ & 2.93 & $\mathrm{td}$ & $J_{\text {gem }} 12.5$ and $J_{6 a, 5} 11.8$ \\
\hline $5-\mathrm{H}$ & 3.88 & $\mathrm{dt}$ & $J_{5,6 \beta} 5.3, J_{5,6 \alpha} 11.9$ and $J_{5,3} 4.6$ \\
\hline $4-\mathrm{H}$ & 4.20 & $\mathrm{t}$ & $J_{4,5}=J_{4,3} 5.3$ \\
\hline $3-\mathrm{H}$ & 4.54 & $\mathrm{t}$ & $J_{3,4}=J_{3,2} 5.3$ and $J_{3,5} 4.6$ \\
\hline $2-\mathrm{H}$ & 4.61 & $\mathrm{~d}$ & $J_{2,3} 5.3$ \\
\hline $7-\mathrm{H}$ & 6.66 & $\mathrm{~s}$ & \\
\hline
\end{tabular}
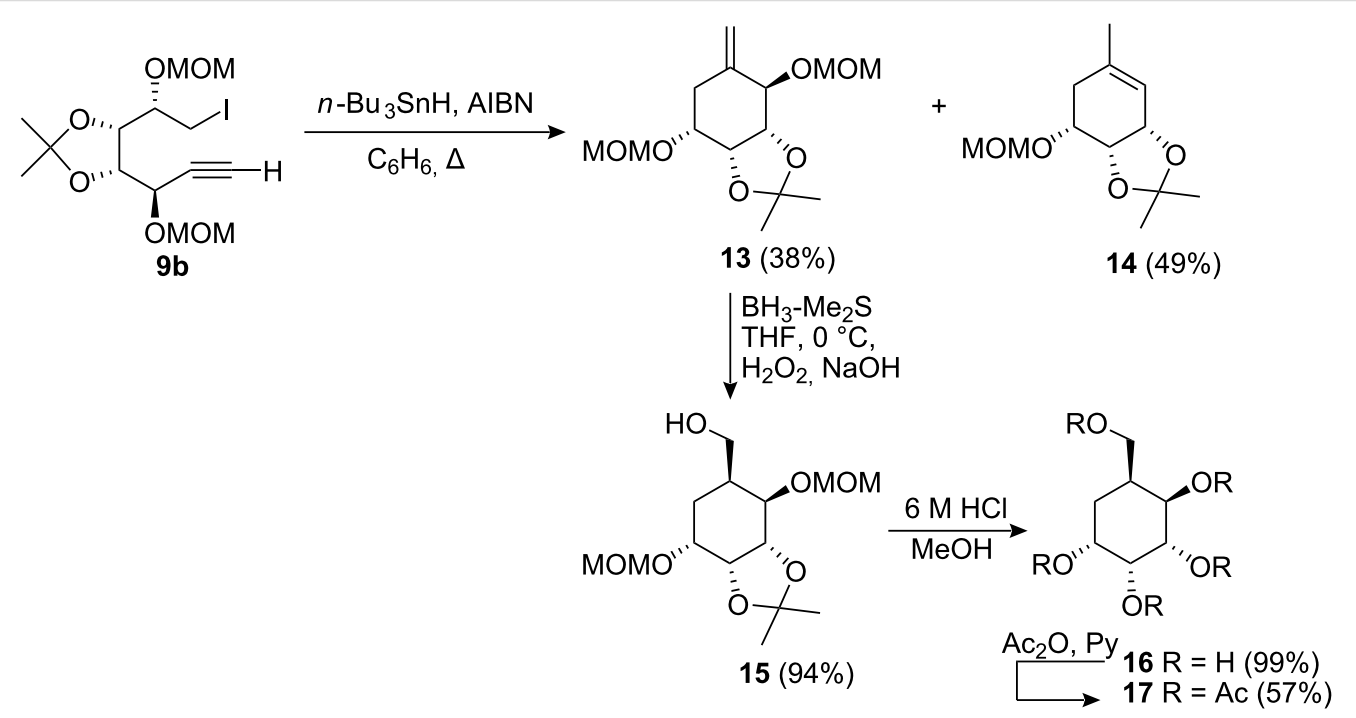

Scheme 3: Radical cyclisation of compound 9b.

a ratio of 1:1.6 as determined by ${ }^{1} \mathrm{H}$ NMR analysis. The diastereomer $7 \mathbf{b}$ on similar treatment underwent a 6-exo-cyclisation and afforded the corresponding cyclohexanes $\mathbf{1 1}$ and $\mathbf{1 2}$ in $61 \%$ yield. In this case we were able to separate the geometric $E$ and $Z$ isomers by silica gel chromatography, in a ratio of $3: 2$, respectively.

The major isomer $\mathbf{1 1}$ was assigned having the $Z$ geometry about the double bond on the basis of NOE experiments. Irradiation of the vinylic resonance at $\delta 6.66$ resulted in enhancement of the aromatic resonances of $\mathrm{H}-6 \alpha$ at $\delta 2.93$, and $\mathrm{H}-6 \beta$ at $\delta 2.39$. Analysis of the ${ }^{1} \mathrm{H}$ NMR data (Table 1) allowed assignment of the stereochemistry at C-2. A large coupling constant $J_{6 \alpha, 5} 11.8$ $\mathrm{Hz}$ at $\delta 2.93$ was observed, which suggests an axial-axial relationship between $\mathrm{H}-6 \alpha$ and $\mathrm{H}-5$, whilst the resonance at $\delta 2.39$, $\mathrm{H}-6 \beta$, showed a coupling constant $J_{6 \beta, 5} 5.3 \mathrm{~Hz}$ indicative of an axial-equatorial relationship.

Having been successful in our initial goal we turned our attention to the preparation of a cyclohexane that had an unsubstituted exo-methylene group. Treatment of the silylated ribose derivative with lithium trimethylsilylacetylide in THF gave the diols $\mathbf{2 b}$, in a combined yield of $45 \%$ along with the alkynes $\mathbf{2 c}$ in $28 \%$ yield. The diastereomeric mixture $\mathbf{2 b}$ was converted to the MOM ethers $\mathbf{4 a}$ and $\mathbf{4 b}$ that could be separated in a combined yield of $64 \%$ with an anti:syn ratio of $3.5: 1$. Both of these diastereoisomers were processed separately. Removal of the silyl protecting group of $\mathbf{4 a}$ and $\mathbf{4 b}$ gave the corresponding primary alcohols $\mathbf{8 a}$ and $\mathbf{8 b}$ in $96 \%$ and $91 \%$ yields, respectively. These compounds were identical to those obtained from 2c after the diastereoisomers had been subjected to protection as MOM ethers on treatment with MOM chloride to give 5a and 5b followed by desilylation, the anti:syn ratio being 2.3:1.<smiles>C=C1C[C@@H](OC)[C@H]2OC(C)(C)O[C@H]2C1OC</smiles><smiles>C=C1C[C@@H](OC)[C@H]2OC(C)(C)O[C@H]2[C@H]1OC</smiles>

Figure 1: Structures of compounds 18 and 19. 


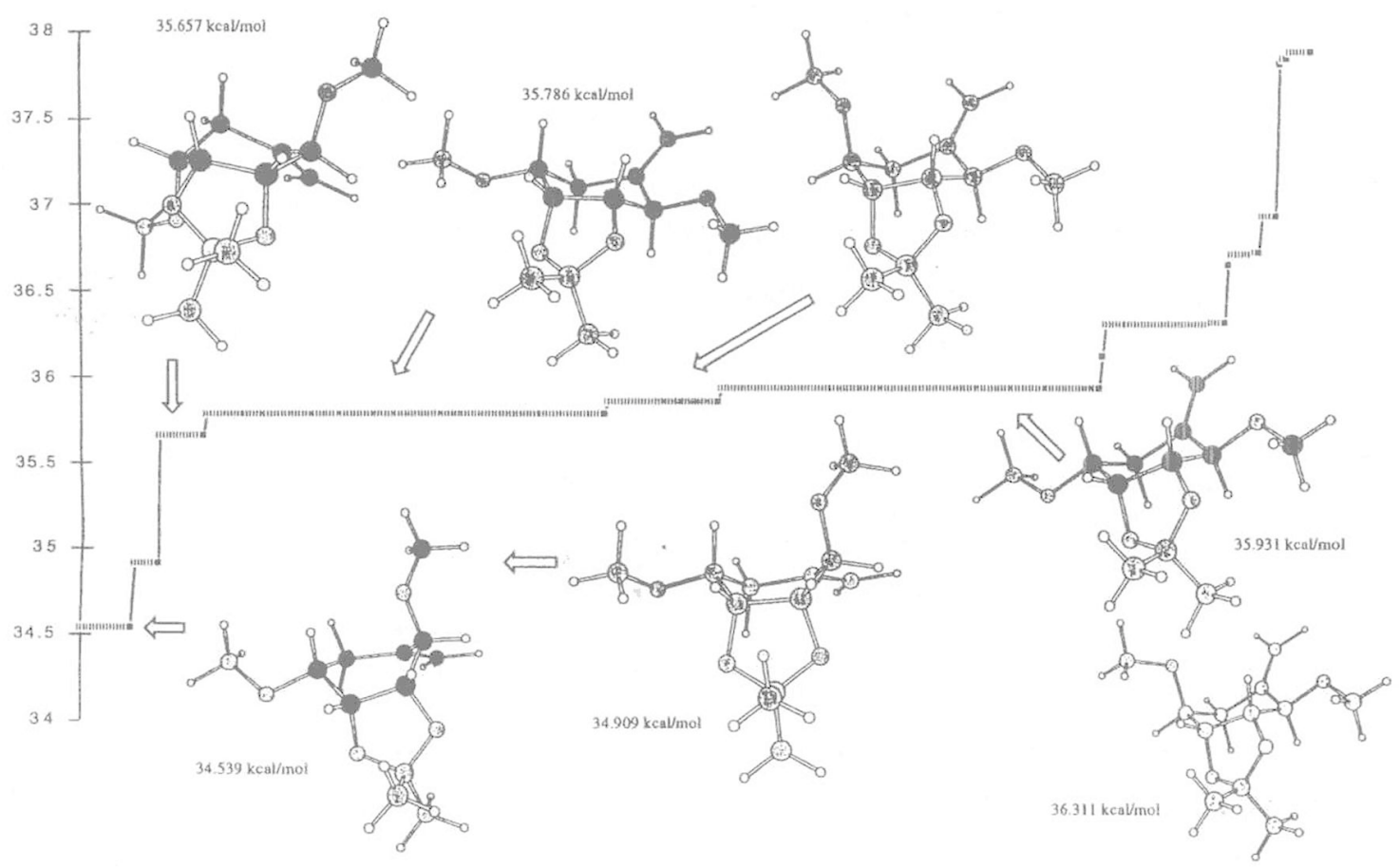

Figure 2: Monte Carlo search on the simplified "trans" structures (structures shown are within $2 \mathrm{kcal} / \mathrm{mol}$ ).

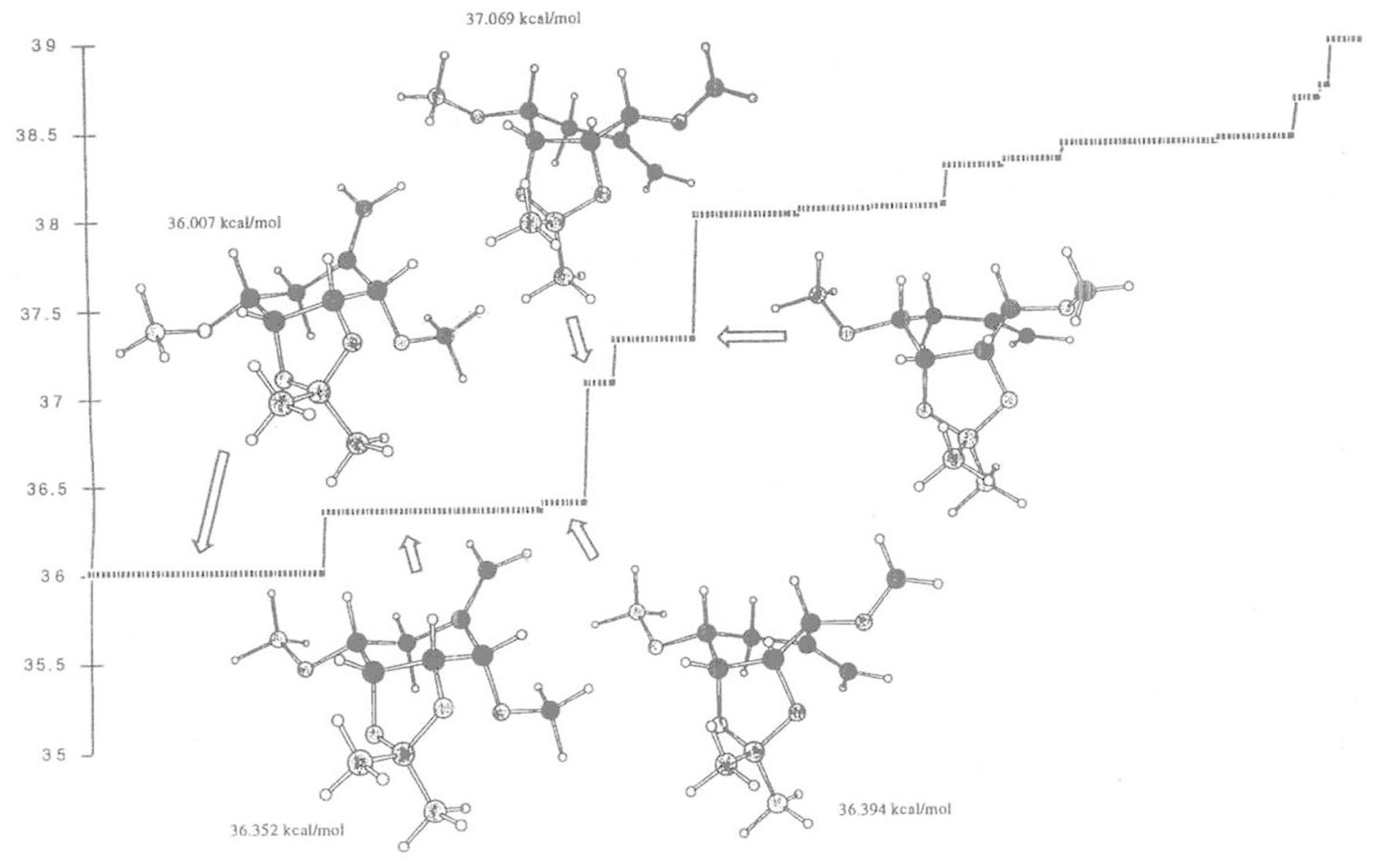

Figure 3: Monte Carlo search on the simplified "cis" structures (structures shown are within $2 \mathrm{kcal} / \mathrm{mol}$ ). 
The $s y n$-product was correlated with the syn isomer 2c [23]. Conversion of the alcohols $8 \mathbf{a}$ and $\mathbf{8 b}$ to the iodides $9 \mathbf{a}$ and $\mathbf{9 b}$ was accomplished by treatment with triphenylphosphine, imidazole and iodine in $73 \%$ and $78 \%$ yields, respectively. At this point we proceeded to investigate the 6-exo radical cyclisation of these iodides. The $s y n$-isomer $\mathbf{9 b}$ was treated with tri- $n$ butyltin hydride and AIBN in refluxing benzene, (Scheme 3) and gave the expected exo-methylene cyclohexane $\mathbf{1 3}$ in 38\% yield along with the cyclohexene 14 in $49 \%$ yield where the OMOM group had been lost. The structure of $\mathbf{1 4}$ was clearly evident from its ${ }^{1} \mathrm{H}$ NMR spectrum which had a resonance only for one MOM group in addition to the observation of a resonance at $\delta 5.33$ due to the vinylic proton and a resonance at $\delta$ 1.73 due the methyl group.

Following these findings we subjected the isomer 9a to the same reaction conditions and we observed that the cyclisation was appreciably slower, taking $24 \mathrm{~h}$ to go to completion. However this reaction was much more selective in that we only isolated $\mathbf{1 4}$ in a yield of $99 \%$. In this case the primary radical formed from the iodide 9a undergoes a 6-exo cyclisation onto the alkyne, which results in the formation of a vinyl radical which is capable of abstracting a hydrogen from the methylene carbon of the OMOM group subsequently followed by $\beta$-scission $[29,30]$ resulting in the formation of an allylic radical which gives rise to the observed product. The formation of $\mathbf{1 4}$ reflects the geometry of the vinyl radical and that these are bent with a bond angle of ca. $135^{\circ}$ whilst in the case of an $\alpha$-phenyl radical the geometry is linear [31]. In order to gain additional insight as to the geometries of the transition state(s) for these processes we undertook Monte Carlo calculations using much simpler structures (Figure 1), in order to simplify the computation, (18 and 19).

At low energies of 34.539 and $34.909 \mathrm{kcal} / \mathrm{mol}$ (Figure 2), the "trans" isomer 18 favours a boat conformation, in which the carbon-carbon double bond is above the plane of the ring and the methoxy group is in axial position and as a consequence the vinyl radical cannot abstract a hydrogen radical from the methoxy group. However at higher energies $35.657 \mathrm{kcal} / \mathrm{mol}$, the "trans" isomer adopts a boat conformation and the ring can flip to different conformations at 35.786 and $35.931 \mathrm{kcal} / \mathrm{mol}$ and allows the radical to abstract a hydrogen atom from the methoxy group (Figure 2). The "cis" isomer 19 favours the chair conformation at low energies $(36.007 \mathrm{kcal} / \mathrm{mol})$ but can flip to the boat conformation more easily $(36.394 \mathrm{kcal} / \mathrm{mol})$ where the vinyl radical (Figure 3) can abstract the hydrogen atom from the methoxy group.

Having established that the 6-exo cyclisation was of synthetic value we proceeded to investigate the possibility of carrying out such a process using a secondary radical and thereby obtaining access to a cyclohexane ring that had substituents on all six carbons. Thus the alcohols $\mathbf{6 a}$ and $\mathbf{6 b}$ were oxidised most efficiently with PCC [32-37] to afford the corresponding aldehydes $\mathbf{2 0}$ and $\mathbf{2 1}$ in $85 \%$ and $90 \%$ yield, respectively. Both these aldehydes were found to be somewhat unstable at room temperature, as evidenced by their polymerisation and hence were used in the subsequent reaction as soon as possible. The aldehyde $\mathbf{2 0}$ was treated with phenylmagnesium chloride in THF and gave a mixture of two-diastereoisomeric alcohols 22 in $72 \%$ yield, which were separated using flash chromatography on silica gel. The stereochemistry at the newly created chiral centre could not be defined at this juncture. However, this was deemed to be unnecessary, as both of these diastereoisomeric alcohols would give rise to the same secondary radical and as a result we employed the diastereomeric mixture $\mathbf{2 2}$ in the subsequent

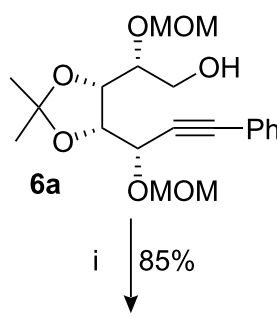

OMOM<smiles>CC[C@H]1OC(C)(C)O[C@@H]1[C@@H](C#Cc1ccccc1)OC</smiles>

20 ŌMOM ii<smiles>[R]C(O)[C@H](OC)[C@H]1OC(C)(C)O[C@H]1[C@H](OC)c1ccccc1</smiles>

$22 \mathrm{R}=\mathrm{Ph}(72 \%)$

$24 \mathrm{R}=\mathrm{Me}(80 \%)$

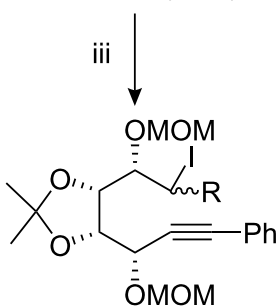

$26 \mathrm{R}=\mathrm{Ph}(78 \%)$ $28 \mathrm{R}=\mathrm{Me}(82 \%)$<smiles>CO[C@@H](CO)[C@@H]1OC(C)(C)O[C@@H]1[C@@H](C#Cc1ccccc1)OC</smiles>

6b i $90 \%$ $\downarrow$ OMOM<smiles>CO[C@@H](C)[C@H]1OC(C)(C)O[C@@H]1[C@@H](C#Cc1ccccc1)OC</smiles>

21 ii $\checkmark$<smiles>[R]C(OC)[C@H](C)[C@@H](C#Cc1ccccc1)OC</smiles>

$23 \mathrm{R}=\mathrm{Ph}(71 \%)$

$25 \mathrm{R}=\mathrm{Me}(79 \%)$

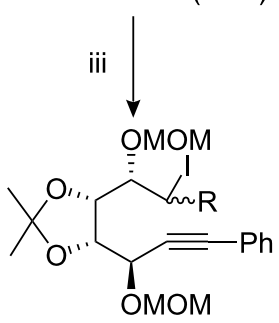

$27 \mathrm{R}=\mathrm{Ph}(73 \%)$

$29 \mathrm{R}=\mathrm{Me}(85 \%)$
Scheme 4: Synthesis of iodides from compounds $\mathbf{6 a}$ and $\mathbf{6 b}$. Reagents and conditions: (i) PCC, $4 \AA$ molecular sieves, DCM, RT, $2 \mathrm{~h}$; (ii) $\mathrm{PhMgCl}$ or $\mathrm{MeMgBr}, \mathrm{THF}, 0{ }^{\circ} \mathrm{C}, 1 \mathrm{~h}$; (iii) $\mathrm{PPh}_{3}$, imidazole, $\mathrm{I}_{2}$, toluene, $60^{\circ} \mathrm{C}, 2 \mathrm{~h}$. 


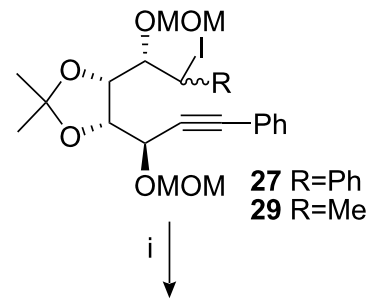<smiles>[R]C1C(=Cc2ccccc2)[C@H](OC)[C@@H]2OC(C)(C)O[C@@H]12</smiles>

$30 \mathrm{R}=\mathrm{Ph}(32 \%)$ $34 \mathrm{R}=\mathrm{Me}(30 \%)$ ii<smiles>[R]C1C(=O)[C@H](OC)[C@H]2OC(C)(C)O[C@@H]2[C@H]1OC</smiles>

$38 \mathrm{R}=\mathrm{Ph}(77 \%)$

$40 \mathrm{R}=\mathrm{Me}(75 \%)$<smiles>[R]C1C(=Cc2ccccc2)C(OC)[C@H]2OC(C)(C)O[C@H]2[C@H]1OC</smiles>

$$
32 \mathrm{R}=\mathrm{Ph}(16 \%)
$$$$
36 \mathrm{R}=\mathrm{Me}(17 \%)
$$

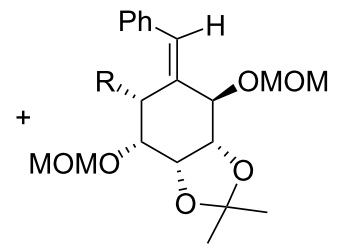

$33 \mathrm{R}=\mathrm{Ph}(19 \%)$

$37 \mathrm{R}=\mathrm{Me}(14 \%)$

$$
\begin{aligned}
& 31 \mathrm{R}=\mathrm{Ph}(24 \%) \\
& 35 \mathrm{R}=\mathrm{Me}(23 \%)
\end{aligned}
$$

ii<smiles>[R]C1C(=O)[C@H](OC)[C@H]2OC(C)(C)O[C@@H]2[C@H]1OC</smiles>

$39 \mathrm{R}=\mathrm{Ph}(74 \%)$

$41 \mathrm{R}=\mathrm{Me}(74 \%)$

Scheme 5: Radical cyclisation of compounds 27 and 29. Reagents and conditions: (i) $\mathrm{Bu}_{3} \mathrm{SnH}, \mathrm{AlBN}$, benzene, $80{ }^{\circ} \mathrm{C}, 3 \mathrm{~h}$; (ii) $\mathrm{DCM}, \mathrm{MeOH}, \mathrm{O}_{3}$, $-78^{\circ} \mathrm{C}, 40 \mathrm{~min}$

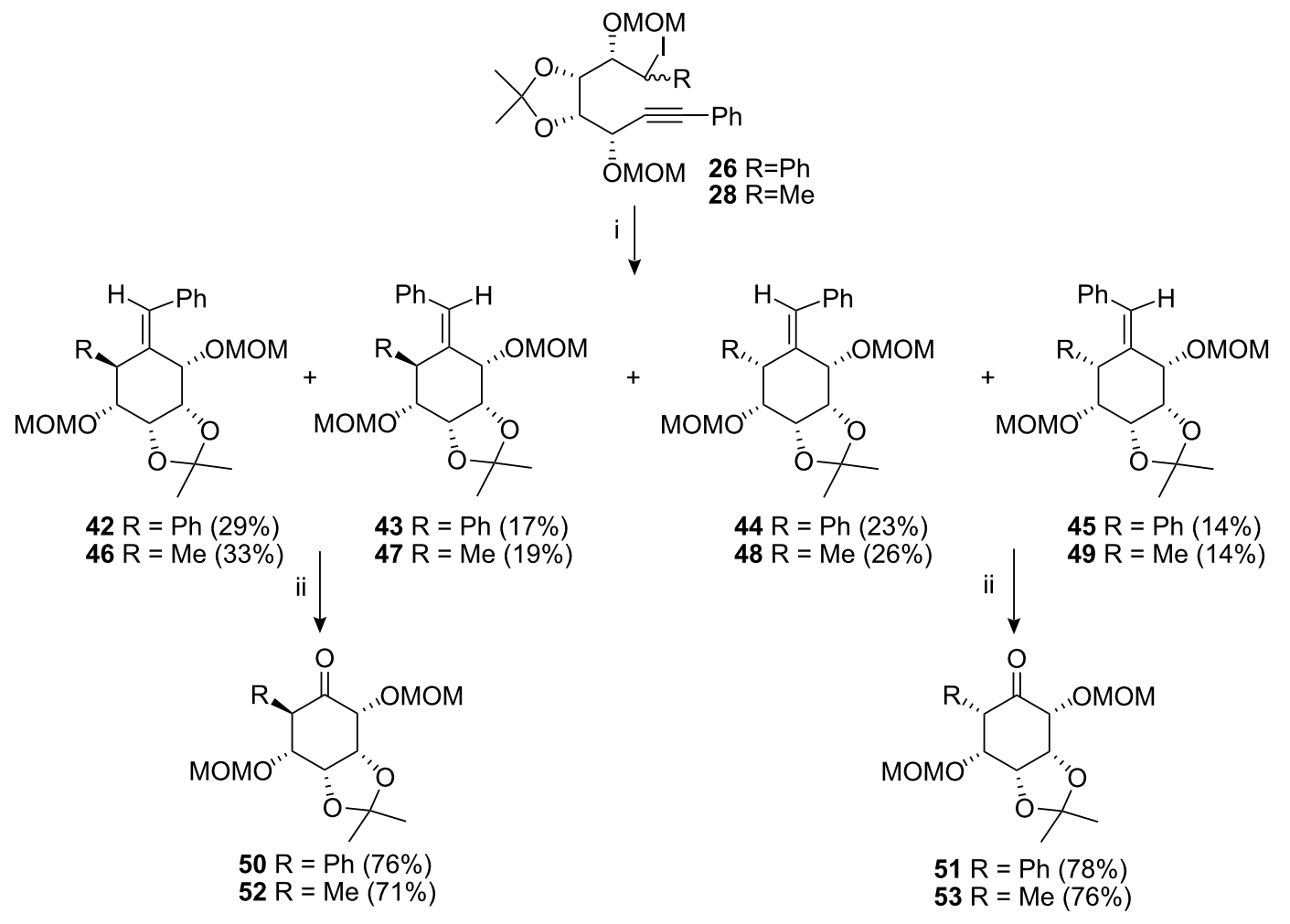

Scheme 6: Radical cyclisation of compounds 26 and 28. Reagents and conditions: (i) $\mathrm{Bu}_{3} \mathrm{SnH}, \mathrm{AIBN}$, benzene, $80{ }^{\circ} \mathrm{C}, 3 \mathrm{~h}$; (ii) $\mathrm{DCM}, \mathrm{MeOH}, \mathrm{O}_{3}$, $-78^{\circ} \mathrm{C}, 40 \mathrm{~min}$. 
chemistry. This mixture of alcohols 22 was converted to the corresponding iodides [25-30] 26 on treatment with triphenylphosphine, imidazole and iodine in $78 \%$ yield. The iodides $\mathbf{2 6}$ were prone to rapid decomposition even when stored at $4{ }^{\circ} \mathrm{C}$ as evidenced by TLC and ${ }^{1} \mathrm{H},{ }^{13} \mathrm{C}$ NMR analysis. Similar chemistry was performed with aldehyde $\mathbf{2 1}$ which gave a mixture of secondary alcohols $\mathbf{2 3}$ in $71 \%$ yield and subsequently the mixture of alcohol gave the corresponding iodide 27 in $73 \%$ yield. Similar treatment of the aldehydes $\mathbf{2 0}$ and $\mathbf{2 1}$ with methylmagnesium bromide afforded the analogous diols 24 and 25 in $80 \%$ and $79 \%$ yields, respectively; these diols were converted to the iodides $\mathbf{2 8}$ and $\mathbf{2 9}$ employing similar chemistry (Scheme 4).

Radical cyclisation of the iodides $\mathbf{2 7}$ was conducted via dropwise addition of tri- $n$-butyltin hydride in refluxing benzene, using AIBN as a radical initiator. This resulted in the formation of the two pairs of diastereoisomers at C-2 and C- 6 along with two pairs of geometric isomers in a combined yield of $91 \%$, (Scheme 5). We were able to separate these isomers successfully by flash chromatography, eluting with light petroleumdiethyl ether (3:1 to 1:1). A similar outcome was obtained for the isomers 26 (Scheme 6) and resulted in a total cyclisation yield of $83 \%$. We also investigated the cyclisation reactions of the "methyl" analogues $\mathbf{2 8}$ and $\mathbf{2 9}$ and these gave a similar outcome, (Scheme 6 and Scheme 5). Ozonolysis of the pair of geometric isomers $\mathbf{3 0}$ and $\mathbf{3 1}$ afforded the protected ketone $\mathbf{3 8}$ in $77 \%$ yield.

The diastereomeric ketone 39 was obtained in 74\% yield after similar treatment of $\mathbf{3 2}$ and 33. Removal of the MOM and isopropylidene with $6 \mathrm{M} \mathrm{HCl}$ resulted in the aromatisation of the ring system. A similar outcome was obtained if we conducted acetylation of the crude reaction mixture in the presence of acetic anhydride and pyridine. In contrast to these findings the protecting groups of the cyclohexane 54, (Scheme 7), could be successfully removed on treatment using these conditions. Hydroboration of cyclohexene $\mathbf{1 4}$ obtained from cyclisation of 9a, following oxidative workup gave the cyclohexanol 54 in $77 \%$ yield. Removal of the isopropylidene and MOM protecting groups afforded a fully deprotected carba- $\beta$-D-rhamnose $\mathbf{5 5}$ in $99 \%$ yield. The structural integrity of $\mathbf{5 5}$ was established by acetylation with acetic anhydride and pyridine which gave the tetraacetate 56 in $99 \%$ yield.

\section{Conclusion}

We have established that carbohydrate derived alkynes undergo 6-exo radical cyclisation and provide access to fully functionalised cyclohexanes and carbasugars which are not easily accessible via other routes.

\section{Supporting Information}

\section{Supporting Information File 1}

Experimental and Data

[http://www.beilstein-journals.org/bjoc/content/

supplementary/1860-5397-4-43-S1.doc]

\section{Acknowledgments}

We thank the EPSRC for access to central facilities for high resolution mass spectrometric data at the University of Wales, Swansea, and FPC for financial support for this research. We thank Professor W. T. Borden for helpful discussions regarding vinyl radicals.

\section{References}

1. Ferrier, R. J.; Middleton, S. Chem. Rev. 1993, 93, 2779-2831. doi:10.1021/cr00024a008

2. Arjona, O.; Gómez, A. M.; López, J. C.; Plumet, J. Chem. Rev. 2007, 107, 1919-2036. doi:10.1021/cr0203701

3. McCasland, G. E.; Furuta, S.; Durham, L. J. J. Org. Chem. 1966, 31 , 1516-1521. doi:10.1021/jo01343a048

4. McCasland, G. E.; Furuta, S.; Durham, L. J. J. Org. Chem. 1968, 33, 2835-2841. doi:10.1021/jo01271a049

5. McCasland, G. E.; Furuta, S.; Durham, L. J. J. Org. Chem. 1968, 33, 2841-2844. doi:10.1021/jo01271a050

6. Lopez, J. C.; Fraser-Reid, B. Chem. Commun. 1997, 2251-2257. doi:10.1039/a704040g

7. Tatsuta, K. J. Synth. Org. Chem., Jpn. 1997, 55, 970-981.

8. Martínez-Grau, A.; Marco-Contelles, J. Chem. Soc. Rev. 1998, 27, 155-162. doi:10.1039/a827155z

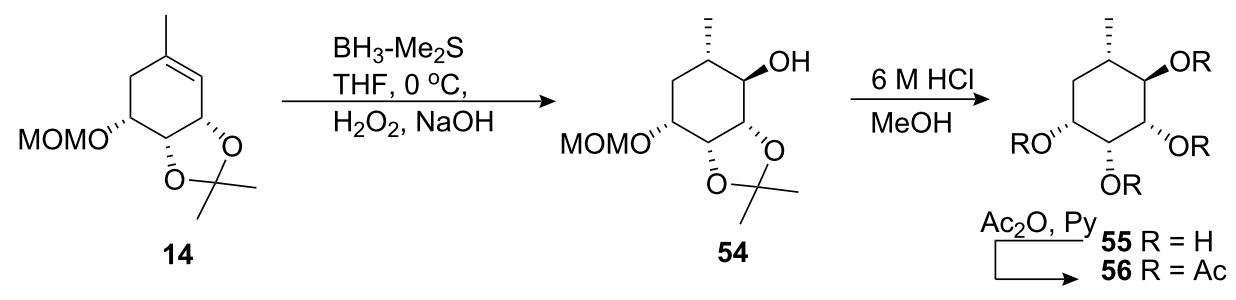


9. Dalko, P. I.; Sinaÿ, P. Angew. Chem., Int. Ed. 1999, 38, 773-777. doi:10.1002/(SICI)1521-3773(19990315)38:6<773::AID-ANIE773>3.0. $\mathrm{CO} ; 2-\mathrm{N}$

10. Berecibar, A.; Grandjean, C.; Siriwardena, A. Chem. Rev. 1999, 99, 779-844. doi:10.1021/cr980033।

11. Giese, B. Radicals in Organic Synthesis: Formation of Carbon-Carbon Bonds; Pergamon Press: Oxford, 1986.

12. Motherwell, W. B.; Crich, D. Free Radical Chain Reactions in Organic Synthesis; Academic Press: London, 1992.

13. Giese, B.; Kopping, B.; Göbel, T.; Dickhaut, J.; Thoma, G.; Kulicke, K. J.; Trach, F. Org. React. 1996, 48, 301-856.

14. McDevitt, R. E.; Fraser-Reid, B. J. Org. Chem. 1994, 59, 3250-3252. doi:10.1021/jo00091a004

15. Beckwith, A. L. J. Tetrahedron 1981, 37, 3073-3100. doi:10.1016/S0040-4020(01)98839-8

16. Beckwith, A. L. J.; Easton, C. J. J. Am. Chem. Soc. 1981, 103, 615-619. doi:10.1021/ja00393a019

17. Malatesta, V.; Ingold, K. U. J. Am. Chem. Soc. 1981, 103, 609-614. doi:10.1021/ja00393a018

18. Beckwith, A. L. J.; Schiesser, C. H. Tetrahedron 1985, 41, 3925-3941. doi:10.1016/S0040-4020(01)97174-1

19. Jenkins, P. R.; Symons, M. C. R.; Booth, S. E.; Swain, C. J. Tetrahedron Lett. 1992, 33, 3543-3546. doi:10.1016/S0040-4039(00)92685-6

20. Maudru, E.; Singh, G.; Wightman, R. W. Chem. Commun. 1998, 1505-1506. doi:10.1039/a802228c

21. Hughes, N. A.; Speakman, P. R. H. Carbohydr. Res. 1965, 1, 171-175. doi:10.1016/S0008-6215(00)80921-0

22. Mekki, B.; Singh, G.; Wightman, R. H. Tetrahedron Lett. 1991, 32 , 5143-5146. doi:10.1016/S0040-4039(00)93450-6

23. Jiang, S.; Singh, G.; Wightman, R. H. Chem. Lett. 1996, 67-68. doi:10.1246/cl.1996.67

24. Garegg, P. J.; Samuelsson, B. J. Chem. Soc., Perkin Trans. 11980 , 2866-2869. doi:10.1039/P19800002866

25. Gómez, A. M.; Danelón, G. O.; Moreno, E.; Valverde, S.; López, J. C. Chem. Commun. 1999, 175-176. doi:10.1039/a808848i For recent 6-exo-dig radical cyclisations leading to carbasugars, see.

26. Gómez, A. M.; Moreno, E.; Valverde, S.; López, J. C. Tetrahedron Lett. 2002, 43, 7863-7866. doi:10.1016/S0040-4039(02)01919-6

27. Gómez, A. M.; Moreno, E.; Danelón, G. O.; Valverde, S.; López, J. C. Tetrahedron: Asymmetry 2003, 14, 2961-2974. doi:10.1016/S0957-4166(03)00532-9

28. Gómez, A. M.; Moreno, E.; Valverde, S.; López, J. C. Eur. J. Org Chem. 2004, 1830-1840. doi:10.1002/ejoc.200300339

29. Rochigneux, I.; Fontanel, M.-L.; Malanda, J.-C.; Doutheau, A. Tetrahedron Lett. 1991, 32, 2017-2020. doi:10.1016/S0040-4039(00)78896-4

30. Malanda, J.-C.; Doutheau, A. J. Carbohydr. Chem. 1993, 12, 999-1016. doi:10.1080/07328309308020114

31. Nicolaides, A.; Borden, W. T. J. Am. Chem. Soc. 1991, 113, 6750-6755. doi:10.1021/ja00018a005

32. Corey, E. J.; Suggs, J. W. Tetrahedron Lett. 1975, 2647-2650. doi:10.1016/S0040-4039(00)75204-X

33. Corey, E. J.; Schmidt, G. Tetrahedron Lett. 1979, 399-402. doi:10.1016/S0040-4039(01)93515-4

34. Omura, K.; Swern, D. Tetrahedron 1978, 34, 1651-1660. doi:10.1016/0040-4020(78)80197-5

35. Albright, J. D.; Goldman, L. J. Am. Chem. Soc. 1965, 87, 4214-4216. doi:10.1021/ja01096a055
36. Mancuso, A. J.; Huang, S.-L.; Swern, D. J. Org. Chem. 1978, 43, 2480-2482. doi:10.1021/jo00406a041

37. Dess, D. B.; Martin, J. C. J. Org. Chem. 1983, 48, 4155-4156. doi:10.1021/jo00170a070

\section{License and Terms}

This is an Open Access article under the terms of the Creative Commons Attribution License

(http://creativecommons.org/licenses/by/2.0), which permits unrestricted use, distribution, and reproduction in any medium, provided the original work is properly cited.

The license is subject to the Beilstein Journal of Organic Chemistry terms and conditions:

(http://www.beilstein-journals.org/bjoc)

The definitive version of this article is the electronic one which can be found at: doi: $10.3762 /$ bjoc. 4.43 